\title{
The adoption of open platform for container bookings in the maritime supply chain
}

\begin{abstract}
Information systems and technologies (IST) have been playing increasingly crucial roles in supporting the smooth running of maritime supply chain operations. The degree of acceptance of IST within the maritime sector as a whole, however, remains fragmented and variable. Some IST products and platforms have entered the market and gained a broad market share, while others are still struggling. This study, based on twenty-five cases, aims to investigate the adoption of IST in a range of organizations in the maritime shipping supply chain. Open platform, a concept first introduced by Maersk Line and IBM in 2018 for inter-organizational information sharing for the maritime supply chain, is used as an exemplar for this study. To the best of the authors' knowledge, this is one of the first studies to conduct a chain-level analysis of IST adoption within the maritime transportation context. The results suggest that the adoption of inter-organizational information systems is largely affected by factors such as industry characteristics, the system's information confidentiality, supply chain trade partners' power, governmental power, and the ownership structure of the organization, among others. Furthermore, these factors have varying degrees of impact across the various organizational tiers in the maritime supply chain, e.g., information confidentiality mainly influences the adoption of forwarders. This study provides broad insights that will be of interest to both the researchers and practitioners in the maritime supply chain, in which the acceleration of digitalization is expected.
\end{abstract}

Keywords: Inter-organizational information system and technology; open platform; maritime supply chain; multi-method; semi-structured interview 


\section{Introduction}

Today's fierce competition is a powerful incentive for supply chain partners to improve operations efficiency, information visibility, and inter-organizational communication in order to increase their competitiveness. Information systems have been identified as key elements in the accomplishment of this goal. It has been widely noted that information systems and technologies (IST) provide various benefits to supply chain management, such as enhancing communication and collaboration between trading partners (e.g., Ke et al., 2009), increasing service quality and productivity (e.g., Wu and Chuang, 2010), and improving efficiency (e.g., Nguyen, 2013). As the primary mode of transportation for global business, maritime transportation has utilized various information systems and technologies (IST), including electronic commerce (e.g., Hsu et al., 2009), information and communication technologies (ICT) (e.g., Harris et al., 2015; Mondragon et al., 2017), and emerging technologies (e.g., Yang, 2019). Maritime shipping services involve the exchange of large numbers of documents and paperwork between multiple organizations, but the use of a unified platform or information system for inter-organizational communication and information sharing is still unpopular (Hsu et al., 2009). This leads to low efficiency and high error rates in this context. The adoption rate of IST for inter-organizational communication and information sharing in the maritime industry is relatively low compared to other industries. For instance, most shippers prefer traditional modes of communication with forwarders or shipping lines, such as telephone and fax (Hsu et al., 2009). Research on the adoption of inter-organizational information systems for communication and information sharing is thus crucial for both theory and practice.

Open platform, introduced by Maersk Line (MSK) and IBM in 2018, is a conceptual platform that allows for inter-organizational communication and information sharing between multiple organizations in international trade contexts (White, 2018). Based on the concept of open platform, IBM, GTD Solution Inc, and MSK jointly developed a platform called TradeLens to improve information sharing and collaboration across the maritime supply chain (TradeLens, 2020). The diffusion of such an open platform and many other similar information systems is still in its infancy. A study of the adoption behavior is therefore necessary as it enriches the understanding of the unique contextual factors influencing the adoption of inter-organizational information systems for communication and information sharing in this industry. The maritime supply chain differs from many other industries in that it involves a significantly larger number of organizations in the chain; these organizations may be based in different countries with different regulations, business practices, and cultures. Moreover, these organizations have diverse preferences toward inter- and intraorganizational information systems, resulting in a high degree of complexity in adopting interorganizational information systems. Furthermore, maritime transportation requires more real-time visibility, efficient data exchange and communication, and better flexibility in order to react to unexpected changes during shipments (Harris et al., 2015). Hence, there is a compelling need to explore the factors influencing the adoption of inter-organizational information systems in the maritime supply chain.

Many existing studies on the adoption of inter-organizational information systems focus on the perspective of a single firm (e.g., de Mattos and Laurindo, 2017; Lin, 2017; Reyes et al., 2016). However, an organization does not survive in isolation. It is highly dependent on other stakeholders 
(Rogers, 1995), and inter-organizational information systems can, therefore, span multiple organizations. Because of this, it is of scientific significance to investigate how decisions are made jointly toward a new information system; this also responds to the call proposed by Baker (2012) and Hsu et al. (2009). This gap is the underlying motivation behind conducting this study at a chain level. The container booking process involves many of the main players in the shipping chain, including shipping lines, forwarders, shippers, and sometimes consignees (Wang et al., 2020). This provides an appropriate context in which to investigate the adoption of open platform and similar information systems in the maritime supply chain.

Despite the advances in research into the adoption of information systems and technologies (IST) overall, there are a limited number of studies that address their adoption in maritime supply chains (e.g., Chao and Lin, 2009; Hsu et al., 2009; Lu et al., 2007; Mondragon et al., 2017; Yang, 2019). More research is needed, as ISTs are developing rapidly, and the diffusion environment is dynamic. Furthermore, theory-building in a research discipline is vital for its development (Wacker, 1998). This aspect is under-developed within the maritime supply chain context, leading to maritime research being viewed as a body of knowledge without organizational theoretical bases or theories (Woo et al., 2011). This shortcoming provides the opportunity to extend the current knowledge of innovation diffusion in the field of maritime supply chain.

Though innovation diffusion research in maritime supply chains is still in development, general innovation diffusion research has been around for several decades and is considered as one of the most mature streams of research in information systems (Venkatesh et al., 2007). Previous efforts provide a comprehensive understanding of the adoption factors, including perceived benefits and costs, relative advantage, firm size, and the influence of top management support in the adoption of information systems (e.g., Gunasekaran et al., 2009; Ilin et al., 2017; Lin, 2014; Ngai et al., 2008; Zhu et al., 2006). However, factors identified from other industries or contexts may not be relevant in the adoption of information systems in maritime supply chains (Johns, 2006). A study of the adoption of inter-organizational information systems in the maritime supply chain may potentially complement previous research.

Against the backdrop of the aforementioned gaps, this study seeks to understand the adoption of inter-organizational information systems in the maritime supply chain at a chain level. In particular, the Technology-Organization-Environment Framework (TOE) (Tornatzky and Fleischer, 1990) was employed to guide this study of the adoption of organizations in the chain. Specifically, this research seeks to understand: (a) the factors influencing the adoption of inter-organizational information systems for communication and information sharing in the maritime industry, and (b) whether organizations from multiple tiers in the chain react differently toward the same factors. A multimethod approach was employed in this study. Twenty-five cases were conducted, involving at least two organizations from each tier in the chain. Various salient factors influencing the adoption of open platform and other similar information systems were identified. This study contributes to the streams of research on both information system adoption and maritime supply chains. It extends the TOE framework by applying it in a maritime supply chain context and presenting new salient factors. Further, this work also sheds light on innovation diffusion research in a maritime supply chain context. Finally, the results provide practitioners in the shipping chain with a comprehensive 
overview of the adoption of inter-organizational information systems.

The rest of the paper is organized as follows. First, a brief overview of the maritime supply chain and the container booking process is provided, followed by a discussion of earlier studies of the Technology-Organization-Environment (TOE) framework. The third section outlines the methodology of this research, including company selection, data collection, and data analysis. Results and discussion are presented in Section 4, followed by the contributions, implications, limitations, and future research opportunities in Section 5 and conclusion in Section 6.

\section{Practical and Theoretical Background}

\subsection{Overview of Maritime Supply Chain and Container Booking Process}

The maritime supply chain is a traditional business that has been active for centuries; the first cargo moved on the sea more than five thousand years ago, and maritime transportation became the engine of global development. To date, container shipping has been the primary method for global transportation due to its low cost and high efficiency (Yang, 2019), carrying $89.6 \%$ of the total volume of international trade and $70.1 \%$ of the total value. However, the industry is facing tremendous challenges. Ocean freight has steadily declined, and the market has continued to suffer from the weakening demand and increasing capacity of container vessels entering the market. Since 2010, the growth of the world's GDP has been less than the increase in shipping capacity. In 2010, the growth rate of the GDP was 4.327 percent, and that percentage has since fallen to 2.438 (UNCTAD, 2016). The change in China is more significant, dropping from 14.23 in 2007 to 6.7 percent in 2016. Moreover, the total value of exports has also experienced a considerable decline. The growth rate has declined since 2011, and the value of exports fell between 2014 and 2016. Additionally, the cost of global export has increased annually, from 1,181 USD per container in 2007 to 1,560 USD per container in 2014 (UNCTAD, 2016). The same phenomenon was observed for the cost of imports; the fare rate increased from 1,392 USD per unit in 2007 to 1,877 USD in 2014 (UNCTAD, 2016). Though the growth rate of maritime transport experienced a slight decline, the revenue of the maritime transport business would rise due to planned initiatives such as the Belt and Road Initiative. Additionally, trends such as Industrial 4.0, big data, blockchain, interorganizational information systems, and electronic commerce would also contribute to this industry (UNCTAD, 2016; UNCTAD, 2019; WTO, 2019).

The maritime supply chain is complex as it involves partners across different departments and countries with diverse regulations and business practices. van Baalen et al. (2009) have pointed out that forty different organizations might be involved, and hundreds of documents are exchanged when dealing with one container. Manual work is still considered as the main approach in this process. Moreover, ISTs used by organizations also differ, causing considerable inefficiencies within the booking process of the container shipping industry. There is no unified standard or type of information system employed by the whole supply chain. Organizations, such as shipping lines, technological firms, and governmental organizations, started to develop different platforms or products a few years ago to solve the current problems and achieve higher levels of competitiveness. However, while some of them succeeded, gaining wide coverage in the industry (e.g., INTTRA, 
GT-Nexus, CargoSmart, and EMP), others are still struggling (e.g., Onetouch). In addition, tech start-ups are also entering the market, such as YUNQUNA and Flexport.

Container booking activity is considered as the starting point of the whole maritime transportation. In this study, a broad concept of the container booking process is adopted. The process involves a series of activities from the initial request of booking a container, the release of container from shipping line and the loading of the container, to the arrival of the container in the port, and its release by the customs offices. Normally, the shipper sends the booking request to the second-tier or first-tier forwarder, who then communicate with their "supplier", who could be the first-tier forwarder or the shipping line (Hsu et al., 2009). Information relating to the container booking request and the container itself is transferred back and forth between these organizations until the process is complete. In addition, there are also other organizations that are relevant during the booking process, such as the inland transportation agents, the terminal authority, customs, and so forth.

As shown in Figure 1, the classic mode of communication and information sharing between each organization in the booking chain is complex. Furthermore, as mentioned above, this process largely relies on paper and manual work, which renders it costly and time-consuming. Centralized interorganizational information systems allow all the main supply chain partners in the booking chain to share information and communicate more effectively and efficiently. Around ten percent of the cost of global trade could be saved through the implementation of a more efficient process (White, 2018). Open platform not only considers the processes relating to supply chain partners for booking but also other processes and organizations for the whole maritime supply chain. It could be considered as a representative information system for inter-organizational communication and information sharing in the maritime supply chain.
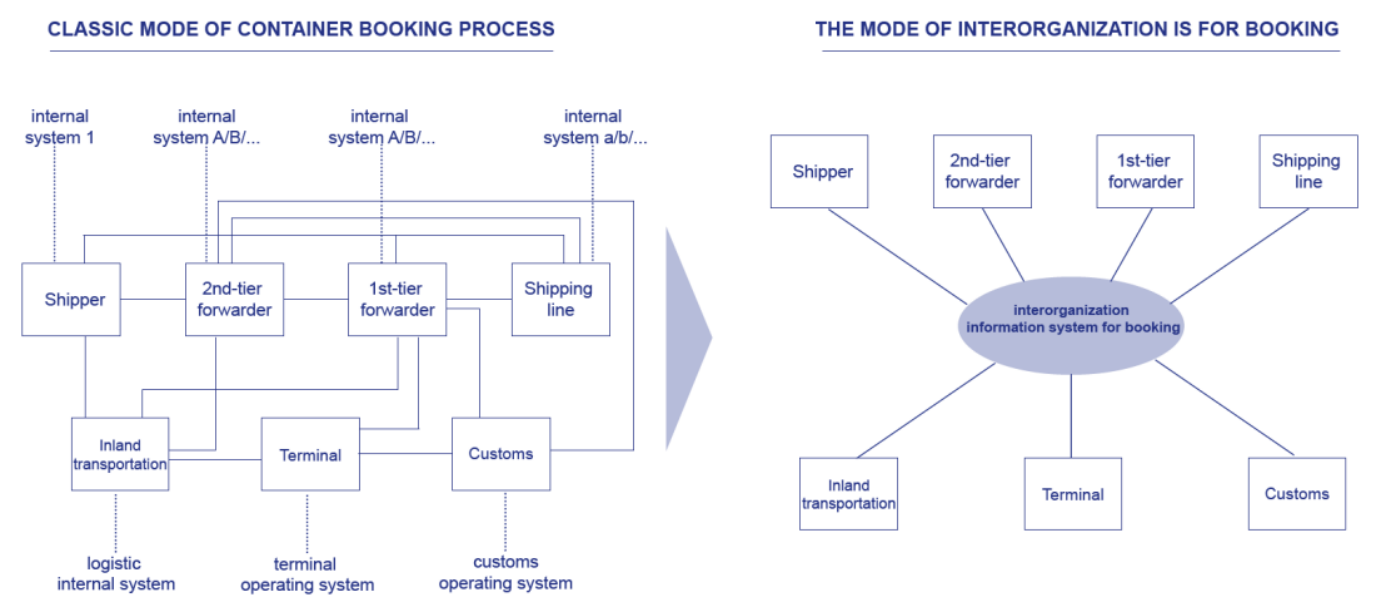

Figure 1. A comparison of the classic mode and the 'new' mode with an inter-organizational information system for container booking.

\subsection{Technology-Organization-Environment (TOE) Framework}


The TOE framework is a firm-level theory that addresses three groups of contextual factors influencing the adoption of technological innovation (Torntzky and Fleishcher, 1990). These three groups are the technological context, organizational context, and environmental context. The technological context refers to "the internal and external technologies relevant to the firm" (Oliveira and Martins, 2011), which could include technologies both adopted and not adopted by the organization (Baker, 2012). The organizational context includes the characteristics and resources of the firm, including firm size and top management support (e.g., Wang et al., 2010). The environmental context is the environment in which the organization conducts business, including the regulatory environment and the structure of the industry (e.g., Ilin et al., 2017).

Much prior research, relating to both the supply chain and other contexts, on the diffusion of innovation at firm level has applied the TOE framework (e.g., Wei et al., 2015; de Mattos and Laurindo, 2017) to explain the adoption behavior of a number of innovations such as e-business (e.g., Ilin et al., 2017), Electronic Data Interchange (EDI) (e.g., Kuan and Chau, 2001), Radio Frequency Identification (RFID) (e.g., Wang et al., 2010), and emerging technologies like the Internet of Things (IoT) (e.g., Tu, 2018) and Artificial Intelligence (AI) (e.g., Alsheiabni et al., 2019), across multiple contexts including supply chains (e.g., Tu., 2018), manufacturing (e.g., Oliveira et al., 2014), healthcare (e.g., Cao et al., 2014), and the grocery industry (e.g., Kurnia et al., 2015). TOE has been employed in extant studies for the purpose of theory-building (e.g., Ahmed et al., 2020; Kurnia et al., 2015) and theory-testing (e.g., de Mattos, 2017; Wei et al., 2015). The TOE framework is a broad and generic theory (Cao et al., 2014); many prior studies have applied the TOE framework as the basis of their research and used unique factors for technological, organizational, and environmental contexts. For instance, Zhu et al. (2006) identified technology readiness and technology integration for the technological context of e-business diffusion, which differs from the original factors in the technological context, i.e., availability and characteristics (Tornatzky and Fleischer, 1990). Therefore, factors identified in previous studies may not be applicable to the adoption of inter-organizational systems in the maritime supply chain.

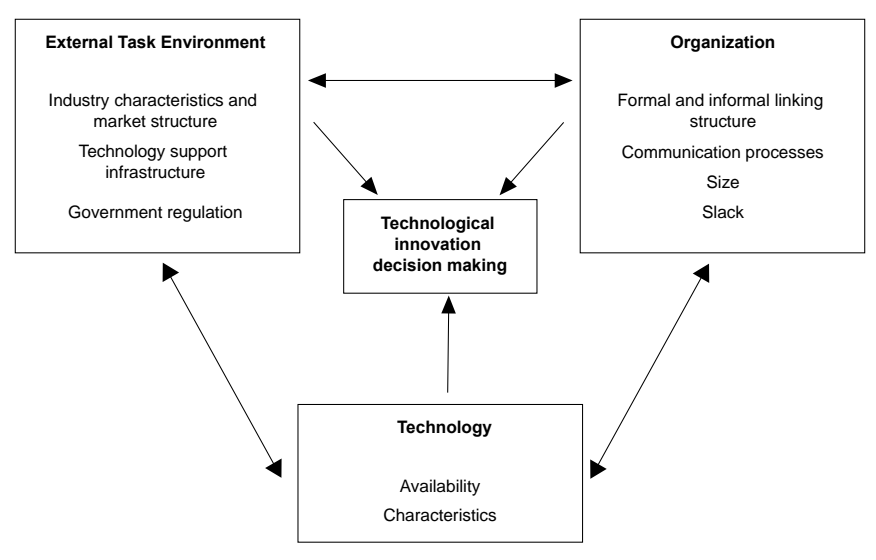

Figure 2. The Technology-Organization-Environment (TOE) Framework (Tornatzky and Fleischer, 1990)

Clearly, many factors are associated with the adoption of inter-organizational information systems at firm level (e.g., Kurnia et al., 2015; Oliveira et al., 2014; Wei et al., 2015). In order to enhance the overall understanding of the key factors identified in the past, a review of the prior literature on 
information system and technology adoption within the context of supply chain management was conducted. The results were classified into three groups: technological context, organizational context, and environmental context of the TOE framework (Tornatzky and Fleischer, 1990). The summary of adoption factors is illustrated in Table 1. The results of the literature review were then used as guidance in the stage of data collection and data analysis.

\begin{tabular}{|c|c|}
\hline \multicolumn{2}{|c|}{ Literature Review Summary in SCM: Adoption Factors } \\
\hline Adoption Factors & Reference \\
\hline \multicolumn{2}{|r|}{ Technological factors } \\
\hline Relative advantage & Wu and Chuang (2010); Tsai et al (2010); Wang et al (2010); Oliveira et al (2014); Ilin et al (2017) \\
\hline Perceived benefits & $\begin{array}{l}\text { Quetti et al (2012); Adebanjo and Laosirihongthong (2014); Lin (2014); Kurnia et al (2015); Tu } \\
\text { (2018) }\end{array}$ \\
\hline Complexity & Power and Simon (2004); Wu and Chuang (2010); Wang et al. (2010); Oliveira et al (2014); \\
\hline Compatibility & Wang et al (2010); Oliveira et al (2014); Harris et al (2015); Kurnia et al (2015); \\
\hline Cost & Power and Simon (2004); Lin (2014); Kurnia et al (2015); Reyes et al (2016); Tu (2018); \\
\hline Perceived east of use & Bienstock et al (2008); Aurty et al. (2010); Cheng and Yeh (2011) \\
\hline Perceived usefulness & Bienstock et al (2008); Aurty et al. (2010); Cheng and Yeh (2011) \\
\hline Security concern & Illin et al (2017); Wu and Chuang (2010); Tu (2018) \\
\hline Task-technology fit & Cao et al (2013) \\
\hline Technological readiness & Oliveira et al (2014) \\
\hline Explicitness of technology & Lin and $\mathrm{Ho}(2009)$ \\
\hline Accumulation of technology & Lin and $\mathrm{Ho}(2009)$ \\
\hline Difficulty of implementation & Power and Simon (2004); \\
\hline \multicolumn{2}{|r|}{ Organizational factors } \\
\hline Top management support/commitment & $\begin{array}{l}\text { Ang et al. (1995); Luken and van Rompaey (2008); Gunasekaran et al (2009); Kim et al (2012); } \\
\text { Oliveira et al (2014); Lin (2014); Kurnia et al (2015); Reyes et al (2016); llin et al (2017) }\end{array}$ \\
\hline Firm size & Lai (1999); Wang et al (2010); Oliveira et al (2014); Harris et al (2015); Kurnia et al (2015) \\
\hline Workforce & Lai (1999); Abdinnour-Helm et al. (2003); Craighead and Laforge (2003) \\
\hline Organizational readiness & Tsai et al (2010); Quetti et al (2012) \\
\hline Absorptive capacity & Lin (2014); Wei et al (2015) \\
\hline Quality of human resources & Lin and $\mathrm{Ho}(2009)$ \\
\hline IT infrastructure & Wei et al (2015) \\
\hline Internal encourangement for innovation & Lin and $\mathrm{Ho}(2009)$ \\
\hline Use of IT & Lai (1999) \\
\hline \multicolumn{2}{|r|}{ Environmental factors } \\
\hline Policy/regulation & $\begin{array}{l}\text { Luken and van Rompaey (2008); Harris et al (2015); Kurnia et al (2015); Ilin et al (2017); } \\
\text { Mondragon et al (2017); }\end{array}$ \\
\hline Environmental uncertainty & Lin and $\mathrm{Ho}(2009) ; \mathrm{Wu}$ and Chuang (2010); Wei et al (2015) \\
\hline $\begin{array}{l}\text { Stakeholder pressure. } \\
\text { (trade partner, competitor, government) }\end{array}$ & Cheng and Yeh (2011); Wang et al (2010); Lin and Ho (2009); Lin (2014); Tu (2018) \\
\hline Market pressure & Luken and van Rompaey (2008); Quetti et al (2012) \\
\hline Global generalization & Luken and van Rompaey (2008) \\
\hline Influence of large organization & Ke et al (2009); Kurnia et al (2015); Mondragon et al (2017) \\
\hline Perceived institutional pressure & Ke et al (2009); Liu et al (2010) \\
\hline
\end{tabular}

Note: Journal papers were identified between 1990 and 2018 in the SCOPUS, Web of Science, and ProQuest. Keywords used for the search were related to adoption (e.g., diffusion, adoption, assimilation), information systems (e.g., information system, information technology, ERP, RFID, EDI, ICT), and supply chain management (e.g., supply chain, operation management, logistics, transportation, manufacturing)

Table 1. Literature Review Summary Regarding Supply Chain Management: Adoption Factors

\section{Methodology}

Following Chan and Reiner's (2019) method, this paper adopted a multi-method approach. It employed the case study as the main method, supplemented by a literature review and publicly available data (such as online news, official websites, and company annual reports) to analyze the current booking process and the adoption factors relating to open platform (Choi et al. 2013; Smart et al. 2010). As Choi et al. (2016) suggest, the multi-method approach enables researchers to investigate the problem from different perspectives, which can increase the scientific value of the research. The case study method is seen as a suitable approach for the exploration of the relevance of real-world practices (Choi et al. 2016), a topic that is currently lacking studies in the area of 
innovation adoption in supply chain management. This study is by nature exploratory, wherein a case study approach is deployed to collect insightful data and answer "how" and "why" questions (Yin, 2018). Compared with single case studies, multiple case studies are believed to be more compelling and robust as they provide more substantial results (Kurnia et al. 2015). Cases involving different tiers of organizations within the same industry that have direct or indirect relationships are valuable for this study because they provide a more comprehensive understanding of the industry and the adoption of open platform for booking activities.

Data were gathered from both primary and secondary sources. The secondary sources analyzed were discussed with practitioners in semi-structured interviews. The results of the literature review were used to structure the semi-structured interviews and code the data collected from the interviews. This empirical research was carried out in China, mainly in Shanghai and Ningbo city, which represent an appropriate geographical context because of the presence of two world-ranked ports. Shanghai Port and Ningbo-Zhoushan Port play essential roles in the container shipping industry. It is expected that this empirical research could provide a comprehensive overview of the adoption of inter-organizational information systems in the maritime supply chain.

\subsection{Company Selection}

Scholars suggest a sample size from two to fifteen cases (Perry, 1998). However, this study was conducted at a chain level, with four tiers included. Thus, twenty-five companies were selected, and one interview was conducted with each of these companies. All the cases consisted of firms in the maritime shipping industry, with head offices or branches in Shanghai city, Ningbo city, and Taizhou city, China. The containers from Taizhou would normally be sent to Ningbo Port for export. Shanghai and Ningbo Port rank first and third in terms of the throughput of containers (UNCTAD, 2019). It was expected that the data collected in these two regions would provide in-depth insights into the adoption of IST in the maritime supply chain. 


\section{World largest Ocean forwarding firms: TEU turnover (2018)}

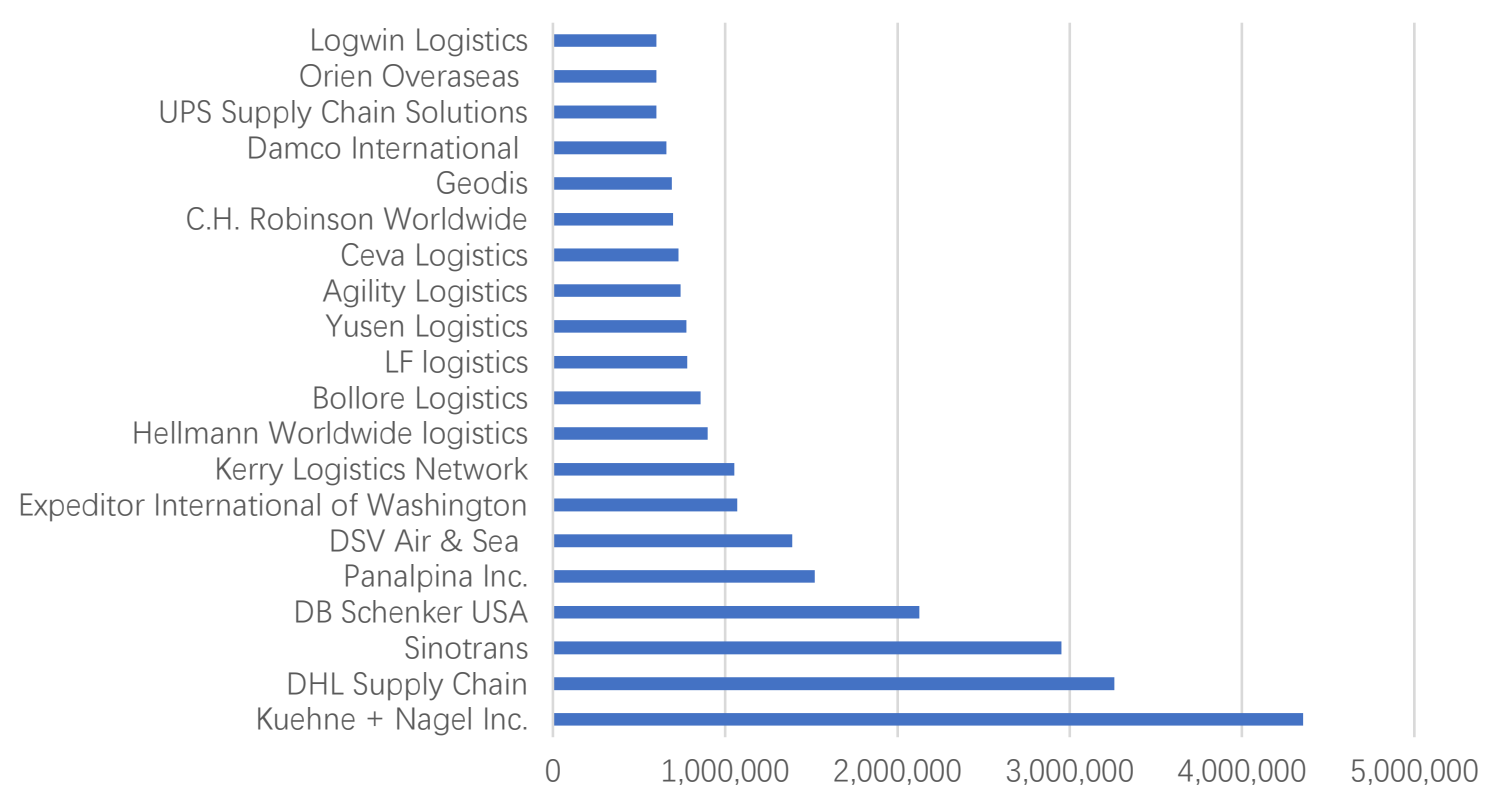

Figure 3. World largest ocean forwarding firms (ranking based on TEU turnover) in 2018 (Bax, 2018)

The maritime shipping industry is considered to be an oligopoly industry to some extent. For instance, from a global perspective, the world's top ten largest shipping companies hold a market share of more than eighty percent (Alphaliner, 2020). The market for ocean freight forwarders shares some characteristics of the shipping line market (see Figure 3). Thus, this study tried to select firms from the main shipping lines and forwarders, which were believed to offer deeper, more advanced research insights. In short, all key members in the container booking chain were included: shipping lines that own the ships, first-tier forwarding firms that book the container space directly from the shipping lines, second-tier forwarding firms that book the container space from the first-tier forwarding firm and communicate directly with the shippers, and shippers or consignees who are the final customers of booking service. At least two firms from each tier were selected to participate in this study. China is a unique context stemming from its cultural, regulatory, and economic conditions (Walsham et al. 2007; Venkatesh et al. 2016), one that incorporates a great variety of ownership structures, such as state-owned, foreign-invested, and privately held companies (Ge and Voß, 2009). Therefore, firms with different ownership structures and characteristics were chosen when the number of each type was greater than one.

Two leading worldwide shipping lines and two leading worldwide first-tier forwarders were chosen in view of their market share or yearly revenue. Three second-tier forwarders that work closely with both the first-tier forwarders and shippers were chosen. In addition, eighteen shippers who are manufacturers and/or traders were selected because they represent the two main groups of shippers in terms of volume. To increase the construct validity, a number of different remedies were deployed: interviewed companies with dyad relationships and key informants such as the general manager, company owner, or senior managers who supervise the booking department to be interviewed. Moreover, these cases represent more than two full booking chains, each of which includes as many players as possible and is expected to have a high degree of validity. These companies enabled us 
to achieve a chain-level view during the investigation of the adoption of inter-organizational information systems in this context. More information about the companies can be found in Table 2 .

\subsection{Data Collection and Analysis}

This study employed semi-structured interviews to collect the primary data. Each interview comprised three sections. The first section covered the general characteristics of the company interviewed and a brief introduction of the interviewee. The second section focused on the container booking process, the tools that were used in the internally and inter-organizational operation process, and the reasons and stages by which the company came to adopt these tools. The third section was designed to explore the opinions and actions of the interviewees or companies in terms of the new types of inter-organizational information systems and technologies that might be utilized in the container booking process, such as open platform.

For each case study, one interview was conducted. An interview invitation containing a brief introduction to the research was sent to the interviewees a minimum of two days before the interview. Interviewees were the key informants, such as the general manager, financial and IT director, and company owner, among others. In order to provide a comfortable and convenient environment, the interviews were performed in the offices or meeting rooms of the interviewees' premises, cafés near the interviewees' homes, and in the interviewer's meeting room, all at the convenience of the interviewees. Each interview lasted approximately 40 to 90 mins. Table 2 displays more detailed information about the participants and the interviews. All interviews were conducted in Chinese, which is the native language of both the interviewees and the interviewer. Before conducting the interviews, participants were informed about their rights and that they could withdraw from the study at any time. They were also assured of their anonymity and the confidentiality of the conversation. Subsequently, the participant consent form and participant information sheet, which had been translated into Chinese in advance, were provided to the participants, and they were asked to sign the consent form.

\begin{tabular}{|c|c|c|c|c|c|c|}
\hline & Interviewee role & $\begin{array}{l}\text { Organization } \\
\text { nationality }\end{array}$ & Organization ownership structure & Role on shipping chain & Location & $\begin{array}{l}\text { Interview } \\
\text { duration }\end{array}$ \\
\hline Company 1 & General Manager & Chinese & State-owned forwarder & First-tier forwarder & Ningbo & $60 \mathrm{mins}$ \\
\hline Company 2 & Finance Director & French & State-owned forwarder & Second-tier forwarder & Shanghai & $50 \mathrm{mins}$ \\
\hline Company 3 & General Manager & Chinese & Non state-owned forwarder & First-tier forwarder & Shanghai & $50 \mathrm{mins}$ \\
\hline Company 4 & Operation Manager & Italian & Non state-owned forwarder & Second-tier forwarder & Shanghai & 40 mins \\
\hline Company 5 & Founder \& Owner & Chinese & Non-state-owned manufacturer \& trader & Shipper & Ningbo & 80 mins \\
\hline Company 6 & Doumentation Manager & French & Non state-owned shipping line & Shipping line & Ningbo & $90 \mathrm{mins}$ \\
\hline Company 7 & Founder \& Owner & Chinese & Non state-owned forwarder & Second-tier forwarder & Ningbo & 60 mins \\
\hline Company 8 & Operation Director & Austrialian & Non state-owned trader & Shipper & Ningbo & $50 \mathrm{mins}$ \\
\hline Company 9 & Founder \& Owner & Chinese & Non-state-owned manufactuer \& trader & Shipper & Ningbo & 40 mins \\
\hline Company 10 & Founder \& Owner & Chinese & Non-state-owned manufactuer \& trader & Shipper & Ningbo & 40 mins \\
\hline Company 11 & Founder \& Owner & Chinese & Non-state-owned manufactuer \& trader & Shipper & Ningbo & $50 \mathrm{mins}$ \\
\hline Company 12 & Founder \& Owner & Chinese & Non-state-owned manufactuerer & Shipper & Ningbo & $50 \mathrm{mins}$ \\
\hline Company 13 & Purchase Director & Chinese & Non-state-owned manufactuerer & Shipper & Ningbo & $50 \mathrm{mins}$ \\
\hline Company 14 & Founder \& Owner & Chinese & Non-state-owned manufactuerer & Shipper & Ningbo & 40 mins \\
\hline Company 15 & Founder \& Owner & Chinese & Non-state-owned manufactuerer & Shipper & Ningbo & 40 mins \\
\hline Company 16 & Sales Manager & Chinese & Non-state-owned manufactuerer & Shipper & Ningbo & 50 mins \\
\hline Company 17 & Founder \& Owner & Chinese & Non state-owned trader & Shipper & Ningbo & 60 mins \\
\hline Company 18 & Founder \& Owner & Chinese & Non state-owned trader & Shipper & Ningbo & 50 mins \\
\hline Company 19 & Founder \& Owner & Greek & Non state-owned trader & Shipper & Ningbo & 60 mins \\
\hline Company 20 & Operation Manager (China area) & Mexican & Non-state-owned trader & Shipper & Ningbo & 40 mins \\
\hline Company 21 & Operation Manager (China area) & Turkish & Non-state-owned manufacturer & Shipper & Ningbo & $80 \mathrm{mins}$ \\
\hline Company 22 & Sales Director & Chinese & Non-state-owned manufactuerer & Shipper & Taizhou & 40 mins \\
\hline Company 23 & Sales Manager & Chinese & Non-state-owned manufactuerer & Shipper & Taizhou & $40 \mathrm{mins}$ \\
\hline Company 24 & Sales Manager & Chinese & Non-state-owned manufactuerer & Shipper & Shanghai & $40 \mathrm{mins}$ \\
\hline Company 25 & Doumentation Manager & Chinese & State-owned shipping line & Shipping line & Ningbo & 50 mins \\
\hline
\end{tabular}


Notes in English were taken during all interviews. Recorded interviews were then transcribed verbatim into full English text and saved as Microsoft Word documents. Notes from non-recorded interviews were also transcribed based on the notes taken. The transcription was structured according to the format of interview questions and produced 200 pages of single-spaced text, making it possible to make comparisons of each subject between individual companies.

The coding schedule proposed by Auerbach and Silverstein (2003) was employed, which consists of five steps: interviews and the preparation of transcripts, coding of the relevant text, categorization of repeating ideas into groups, and further categorization into themes and higher-order theoretical constructs. This was carried out as follows:

- $\quad$ Prepare the transcripts

- Relevant text: read the text with the question in mind, code the relevant text to the question

- Repeating ideas: read the relevant text to identify repeating ideas and code them to groups. Participants may use the same or similar words and sentences to express the same concepts

- Themes: select the groups of repeating ideas and further group them into higher-level themes

- Theoretical constructs: organize the themes into larger and more abstract ideas, which are theoretical constructs

The coding process was conducted manually; as suggested by Saldana (2009), manually coding on paper provides more control over the ownership of the work and provides an opportunity to learn the basics of coding. The results of the literature review were used in the process of coding, with the list of factors being extended to include salient factors that were not identified from the literature review. The coding results are presented in Table 3 . In accordance with the content analysis scheme proposed by Auerbach and Silverstein (2003), the results are illustrated using two levels. The lower level classifies the themes extracted from the relevant text and repeating ideas, and the upper level represents the theoretical constructs that define the theoretical framework of this study. The results of the interviews were finally examined with other researchers to ensure the objectivity of the data analysis.

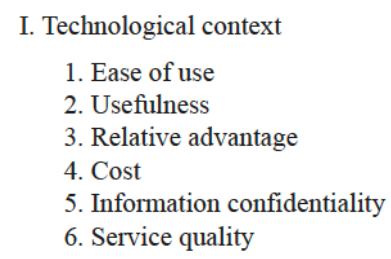

Table 3. List of factors with TOE frameworks for the adoption of inter-organizational information systems (IST)

\section{Results and Discussion}

\subsection{Communication Tools Used in the Container Booking Process}


As mentioned in the previous section, multiple players are involved in the booking process. In the process of booking one container, there is always a container supplier (shipping line), agents (firsttier and/or second-tier forwarders), and a customer (shipper/consignee), all of whom are included in this empirical research. The process begins with a demand for one container/space from the shipper/consignee, followed by the booking service provided by forwarders communicating between the shipper/consignee and shipping line, and finally, the container/space booking operation carried out by the shipping line. Relevant information is then shared and transferred back and forth until the container is loaded onto the ship.

During the investigation, four types of information systems or technologies for booking were identified: (1) Classic inter-organizational information systems such as Electronic Data Interchange (EDI), INTTRA, CargoSmart, and GT-Nexus, an approach mostly employed between the shipping line and first-tier forwarder or large-size direct shipper; (2) E-commerce platforms used by shipping lines and large forwarders, equipped with the booking function; this is mainly used for the purpose of following the status of bookings and vessel information; (3) Third-party booking platforms, representing tech start-ups who provide the same booking services as the traditional forwarder, but with all the operations incorporated into the platform, such as OneTouch, YUNQUNA, and Flexport; none of the cases in this study employed this type; and (4) Traditional communication approaches such as email, telephone, and instant communication tools such as QQ and WeChat. These approaches are adopted by all of the organizations, but they play a more crucial role in the interorganizational communication between lower-tier forwarders and shippers. Figure 4 illustrates the current and most widely used container booking process with inter-organizational communication tools. In general, information-sharing tools such as EDI and e-commerce platforms are employed by higher-tier organizations in the shipping chain, while instant communication tools are used mainly by lower-tier organizations such as second-tier forwarders and shippers. Emails and telephones are adopted by all organizations across the entire shipping chain.

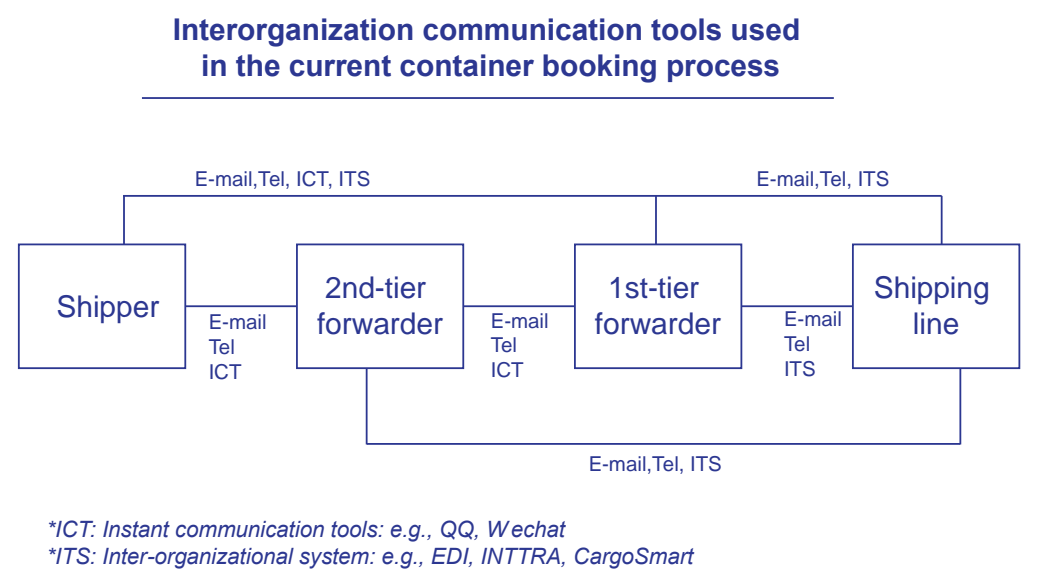

Figure 4. Inter-organizational communication tools used in the current container booking process

\subsection{Adoption Factors Identified}


In this section, factors identified in interviews that affect the adoption of inter-organizational information systems and technologies (IST) are described. The results are explained using the generic TOE framework.

\subsubsection{Technological context}

Within the technological context, four common factors were found to affect almost every case company; these were ease of use, usefulness, relative advantage, and cost. They are consistent with the findings of other empirical studies of both the supply chain discipline and other disciplines such as information systems. Other salient factors that have not achieved a consensus among researchers were also identified during the investigation, including information confidentiality and service quality.

- Information confidentiality

Interviewees, and forwarders, in particular, expressed concerns that information systems would acquire information about customers, such as contact information and rates, and make use of it. On the one hand, users prefer to be able to access data easily, for instance, from the cloud. On the other hand, they are concerned that the information could be used or shared without their permission. This viewpoint is supported by both first- and second-tier forwarders:

"We prefer to develop this kind of information system by ourselves, if we adopt inter-organizational information systems provided by other firms. The information of our customers would be known. There is no way for me to know if the information would be kept as I want or not" (a first-tier forwarder).

"The question is how it (open platform) would keep the information safe, as it will generate an enormous scale of company information. How could we trust it?" (a first-tier forwarder).

"I am not using any inter-organizational information systems for my company; my business is based on customer information. They (the system provider) can steal the customers from me" (a secondtier forwarder).

"I chose HY2000 because it does not require Internet access; the information would only be saved on my computer. Otherwise, my customer information would be collected by the system itself. The system provider could make use of the data if they want... Onetouch provides multiple services that are related to export, such as booking; however, on the one hand, my customers can access all the information, such as prices, and on the other hand, Onetouch can know about my customers. This places me in a very dangerous situation. Thus, I have never thought about using it" (a second-tier forwarder).

In contrast, the shipping lines and some of the forwarders interviewed are more trusting with regard to information confidentiality. A shipping line told us, "Our whole company uses a web-based system provided by CITRIX, and many of our competitors also use the same system. It is safe..." Further, a second-tier forwarder mentioned that "The information in our system is saved on the cloud, the data are safe, we can outsource the information system...". 
- $\quad$ Service quality

Some of the participants are concerned about whether an open platform or other inter-organizational information systems for booking could provide satisfactory service quality. "Booking-related activities are complicated; many issues might happen. Normally I call my forwarder directly if anything urgent happens, and the problem will be solved immediately, but I don't know if there is any place or anyone to call in this kind of urgent situation (if I adopt open platform) " (a shipper).

Moreover, government networks also contribute to the quality of service. Activities carried out during the booking process are relevant to government offices such as port authorities and customs across different countries. Networking with authorities worldwide is vital for providing smooth shipping services. A number of participants said: "When we evaluate the information systems, we also look at their network background. Some information systems might have a strong network in China, but they might be weak in global networks, which would cause inconvenience in our operations" (a second-tier forwarder).

\subsubsection{Organizational context}

In this research, interviewees expressed similar opinions regarding the factors relating to the organizational context.

- $\quad$ Top management support

Top management support is the most crucial factor affecting the diffusion of the electronic booking system within an organizational context. All the interviewees from the various organizations across different tiers mentioned the important role played by top management.

"We have changed our CEO this year, he is relatively young, and he might want something new...our company has formed one team for the development of digitalization within our company" (a shipping line).

"When there is an inquiry for an information system or technology, the management team in our China region would gather together and discuss the necessity. If we agree, then we would either make the decision directly or report it to our head office overseas and apply" (a second-tier forwarder with a head office outside of China).

"I am the owner, so I can make the decision directly whether to adopt an information system or not" (shippers, and a second-tier forwarder).

- $\quad$ Firm size

Firm size is found to affect the decision-making process regarding the adoption of interorganizational information systems for booking. As mentioned, large firms are frequently concerned that information systems will extract information relating to their customer and their transactions, and many prefer to work manually or develop their own booking systems. Small-sized firms, 
however, expressed an inconsistent range of opinions. A second-tier small-sized enterprise that was interviewed stated that they treated customer information as their core value and, as a result, refused to use certain kinds of systems. Meanwhile, a small-sized exporter who participated stated that "I don't feel comfortable when my customer (final customer) information is at the hand of the system provider" (a shipper). Nevertheless, a small-sized manufacturer thought, "I know they will have my information; I do not care. I am small; if they want to make use of the data, they will use the data from big firms" (a shipper). Moreover, large organizations and state-owned organizational bodies face a more complicated application process when purchasing information systems and technologies. "If we (branch in Ningbo) decide to purchase, we should report to our head office in Zhejiang Province; we can only purchase after it is approved by them (a first-tier forwarder)".

- Ownership structure

The effect of ownership structures on the adoption of inter-organizational information systems is novel. Four types of ownership structure were encountered during the investigation, these being foreign state-owned, foreign non-state-owned, Chinese state-owned, and Chinese non-state-owned enterprises. There are legal restrictions on foreign-owned (foreign-invested) companies doing business in China. For instance, shipping lines cannot send certain documents (such as manifests) to customs directly; instead, they should use agents to perform the work. Further,

"...even we know it is not convenient, there is no option for us. We are a foreign shipping line...In China, foreign-owned shipping lines cannot provide trucking services...furthermore, foreign shipping lines cannot send the manifest information to customs directly. It has to be transferred via a middle agent..." (a shipping line).

This restriction would also affect the choice of which system to use. Moreover, state-owned enterprises also have different kinds of restrictions. The general manager of a state-owned forwarder mentioned that: "We are a state-owned firm; if we want to purchase one information system, we need to apply on the governmental platform. We can only adopt after the application is approved". In comparison, there are fewer constraints for Chinese non-state-owned enterprises.

\subsubsection{Environmental context}

The characteristics of the industry and power from different stakeholders-i.e., supply chain partners' power and governmental regulation — were found to be the main influential factors.

\section{- Industrial characteristics}

Unlike industries such as manufacturing or retailing, the activities of the maritime transportation industry are closely related to global economics and politics. The recent trade tension between China and the US is affecting the business of shipping lines and the main forwarders. In this study, interviewed shipping lines, first-tier and second-tier forwarders indicated that they are affected by this tension. Moreover, the activities within the industry are also affected by the governmental regulations from different countries. To date, humans have performed the bulk of the work; 
according to the general manager from a first-tier forwarder, "labor cost is around 80 to 90 percent of our total cost". Further, humans cannot be replaced easily in the booking process. The booking request must be sent to second-tier forwarder manually, and the booking information must be inserted manually into the internal system by the second- and first-tier forwarders. The booking information must be confirmed manually by the staff of the shipping lines. There are more processes like these involved in the shipping chain. This view is supported by the general manager of a firsttier forwarder and the owner of a second-tier forwarder:

"The shipping chain is very complicated, and humans cannot be replaced. There are authorities, shipping lines, and local cultures, and many of the issues appeared need people to deal with" (a first-tier forwarder).

"The booking process is critical, in which many issues might happen, and they are urgent in many cases. The information system or platform might be difficult to reach, but a real person can do it. Shippers are more confident working with us" (a second-tier forwarder).

- $\quad$ Power

The maritime supply chain is a shipping line-centric market, as most of the resources are still controlled by a limited number of shipping lines. As shown in Figure 5, the ten world-leading shipping lines hold more than eighty percent of the total market share (Alphaliner, 2020). The number of organizations in the shipping chain rises when the hierarchical position of the organization decreases (see Figure 6). For instance, the number of forwarders is greater than the number of shipping lines, and the number of shippers is greater than that of forwarders. On the QICHACHA platform, a Chinese firm information searching platform, more than 100,000 forwarders are identified in China in 2020.

\section{World largest shipping line: TEU and market share}

(Jan, 2020)

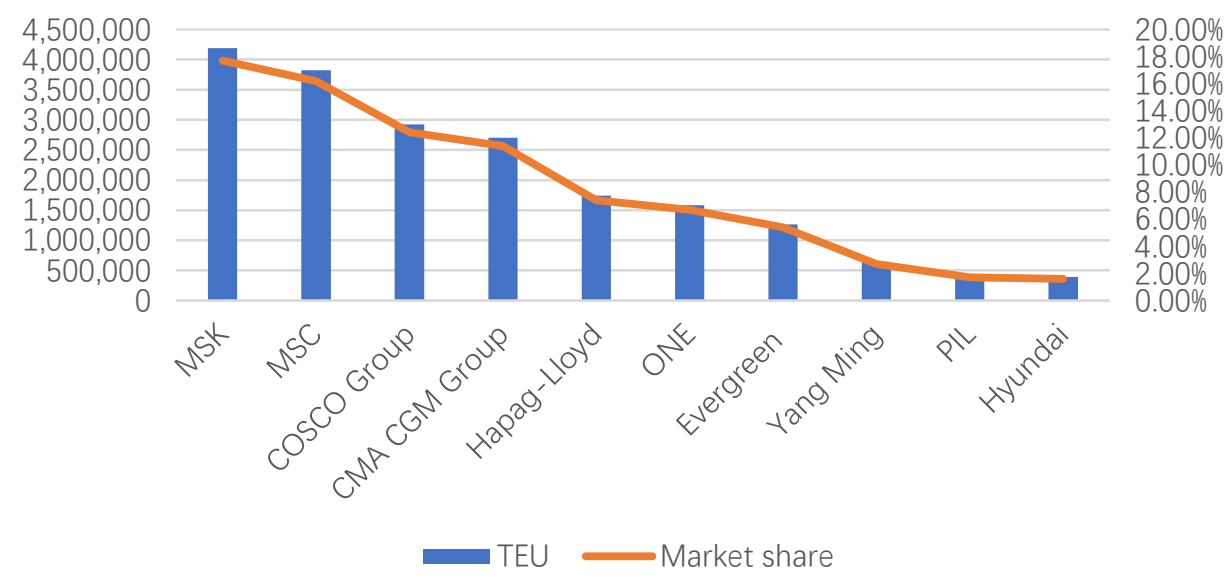

Note: 1. Ranking based on existing fleet and orderbook TEUs available onboard operated ships. 2. All figures are consolidated. 


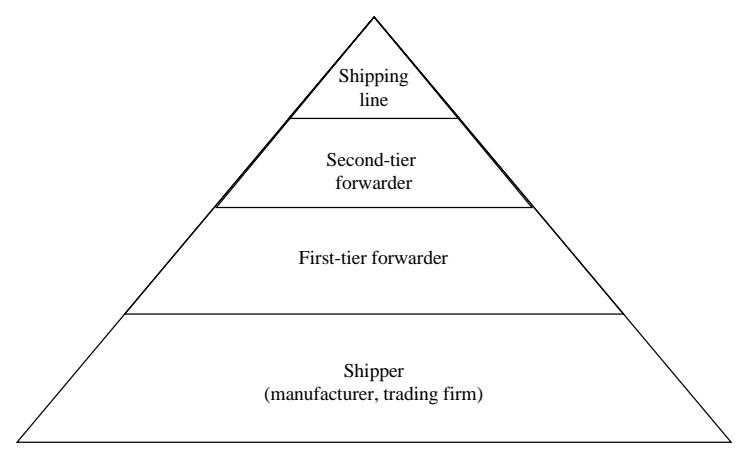

Figure 6. Number of main players in the shipping chain

Power is considered to be a key factor affecting the decision-making process in the adoption of inter-organizational information systems for booking. Three types of power were investigated: power from government, and power from two types of trade partner: customers and shipping lines (suppliers).

Power from government here refers to authoritative power only; the power related to governments as trade partners is not considered. The power from government, which is largely coercive, cannot be underestimated in this industry in terms of the adoption of information systems. It is apparent that, in some cases, governments force shipping chain players to adopt certain kinds of information system, either directly or indirectly. In 2018, China began to request that a new manifest be provided prior to the departure of ships. However, some local governments would not accept manifests from foreign shipping lines directly. The manifest must be transferred by other agents, forcing foreign shipping lines to use certain kinds of agents, some of which are information systems providers. Furthermore, there are also other information systems, such as the Chinaport platform, that are used as the channel for customs-related issues, and the unified $e$-tax platform for export tax-related issues. Shippers do not have the option to adopt or not adopt, or to select between different information systems.

Power from the supplier mainly represents the power from the shipping line. Due to the characteristics of the shipping industry, "shipping lines have direct power in deciding which channel to book" (a first-tier forwarder), and "shipping lines are strong" (a shipping line). This is also supported by the general manager from a first-tier forwarder: "we don't have the option to decide which channel to book; we will follow the channel that the shipping lines ask". Different shipping lines have different preferences; some prefer INTTRA, while others prefer CargoSmart, EMP, and EDI, among others. In general, the options are limited. However, this constraint is mainly applicable to shipping lines and forwarders and is not a concern of shippers, especially small-sized shippers. The owner of a shipper supported this view: "Booking is only a smart part of our work; the cost is also relatively low. I don't even mind processing it manually".

Power from customers exists between shipping lines and large customers who are shippers or consignees (receivers of the goods). Large and international customers such as ZARA and IKEA could choose to use EDI or other inter-organizational information systems to book directly with the shipping lines. Shipping lines follow requests from customers. However, this type of decision is 
between the respective head offices and is not made by local branches. For example, if ZARA is going to work with a shipping line, and EDI is preferred in the booking process, the head office of ZARA would sign the agreement with the head office of the shipping line. Undoubtedly, large customers will always have coercive power over the first- and second-tier forwarders. However, no supported or non-supported evidence was available for this study. Conversely, forwarders provide a variety of booking channel options to shippers: "We can accept EDI, emails, telephones, even fax for booking, though only one customer (shipper) still uses fax to book. Though we have preferences, we don't mind which channel our customers choose" (a first-tier forwarder); "our customers have different preferences; I can accept all of them, either emails, telephones, or instant chatting tools like wechat (from China)... We don't have EDI or other information tools like that, but we also do not have customers who need this kind of channel" (a second-tier forwarder).

- Institutional environment

The institutional environment is the environment in which organizations survive. The adoption behavior regarding inter-organizational information systems is affected by this environment. This view is supported mainly by forwarders and shipping lines:

"In Korea and Taiwan, the booking still proceeds manually. The digitalization rate is very low...though this industry has a low digitalization rate, it is much better in China" (a shipping line).

"Our industry has not yet reached full visualization; if the whole shipping chain becomes fully visualized, then I think the time has arrived (to adopt the MSK \& IBM platform)" (a first-tier forwarder).

"In Ningbo, we do not offer options for customers to choose booking. In cities like Shenzhen, it is more flexible" (a shipping line).

"In Ningbo, there are much fewer options because the digital environment is slower than in Shanghai, such as the EDI environment...the capacity for system development also seems to be a bit slower than Shanghai...In Ningbo, forwarders only use one kind of booking channel to make the process easier" (a shipping line).

"The market of container shipping is more mature in using technologies; thus, INTTRA is considered a bit out of date. There are also more advanced information systems to choose for us" (a shipping line).

The industry's digitalization environment was also found to have an impact on adoption. "The digitalization rate in the shipping industry is low compared with other industries...This industry is not in favor of new innovations" (a second-tier forwarder). This environment would further affect the adoption decisions regarding certain electronic booking systems. As the general manager of a second-tier forwarder mentioned, "the visualization of this industry is low. I would consider accepting blockchain-related systems in our process when our industry reaches a certain high level of visualization".

\subsection{Discussion}


This study uses a multi-method approach to better understand the factors affecting the diffusion of inter-organizational information system in the maritime supply chain. The use of multiple case studies has helped us to develop a better understanding of the container booking process and the tools used in this process and to identify factors influencing the adoption of inter-organizational information systems for booking, such as open platform. The results unearthed several salient adoption factors, which will be discussed under the generic TOE framework below.

Technological Context. Within the technological context, factors identified from previous studies - i.e., ease of use, usefulness, relative advantage, and cost - were found to have an impact on the adoption behavior relating to open platform and other inter-organizational information systems. Moreover, information confidentiality was found to play a significant role when organizations were considering the adoption of inter-organizational information systems. With the development of blockchain technologies, researchers are paying increasing attention to this issue. For instance, Choi et al. (2020) built a stylized duopoly model to analyze the Nash productinformation-disclosure game between rental service platforms. However, while researchers and practitioners call for a higher degree of integration and information sharing in supply chains, less attention has been paid to the confidentiality of digital assets (Massimino et al. 2018). Forwarders are relatively more sensitive about the confidentiality of information, which is not surprising because the information of customers (shippers and consignees) is the primary asset of servicing firms like forwarders. In general, organizations in the shipping chain have diverse views toward information confidentiality. Shipping lines and shippers, for example, are less concerned about the issue. One plausible explanation is that these two tiers of organizations cannot be replaced easily.

Secondly, service quality was found to have an impact on the adoption of inter-organizational information systems in the maritime supply chain. The maritime transportation industry has a significant need for real-time information visibility and efficient data exchange (Harris et al. 2015); one minor error during the information sharing process may cause substantial financial losses. Thus, on-time service is a necessity for many users in the shipping chain. Moreover, organizations consider the networks of inter-organizational information systems with governments as an important factor, as they ensure smooth exporting and importing processes.

Organizational Context. Within the organizational context, top management support and firm size were found to influence the adoption of inter-organizational information systems in the maritime supply chain, which is consistent with prior literature (e.g., Ilin et al. 2017; Oliveira et al. 2014). Top management support is vital for all participating organizations; however, the scope of top management differs between cases. For small organizations, top management refers to the owner of the company, while for large organizations, top management might be a group of department managers working for the organization in one region, e.g., Asia-Pacific, or at their headquarters. Moreover, firm size is found to have a relatively negative effect on adoption processes analyzed in this study. Previous studies identified both positive and negative roles for firm size in the adoption of information systems (e.g., Oliveira et al. 2014; Rogers, 1995; Wang et al. 2010; Zhu et al. 2003). One explanation provided by the participants was that the larger the organization, the more complex the decision-making process will be; though large organization tends to have more of the resources required for adoption (Rogers, 1995). 
Further, the effects of different ownership structures were identified in this study. China provides a unique context in which to investigate the diffusion of innovation (Venkatesh et al. 2016). One explanation for this is that there are organizations with multiple ownership structures. To look further into this issue, organizations with diverse ownership structures were selected for the purposes of this study. The results showed that foreign-invested firms and Chinese state-owned firms face more constraints when deciding whether or not to adopt an inter-organizational information system, as the activities of the former are more restricted by local regulations and the latter experience more complicated decision-making processes.

Environmental Context. Within the context of the environment, the characteristics of the industry were considered as a constraint in the adoption of inter-organizational information booking systems. The activities of the maritime supply chain are highly affected by economics, politics, and governmental regulations. Furthermore, the container shipping industry has a long history and is highly complex with lot of legacy systems and processes. Humans cannot be easily replaced. Nevertheless, many of the activities involved require human intervention in order to proceed. During the investigation, it was found that the digitalization rate of this industry is low in comparison to other industries, which, in turn, leads to greater concerns regarding the adoption of inter-organizational information systems for enterprises. It was also observed that the effects of industrial characteristics exist across different tiers of players, which includes the shipping line, first- and second-tier forwarders, and shippers.

Moreover, power was found to play a vital role in the adoption of inter-organizational information systems. Three types of power were investigated: power from authorities, power from customers, and power from suppliers. Coercive power from authorities exists over enterprises in decisions relating to the adoption of inter-organizational information systems for booking-related processes, such as the adoption of the $e$-tax and Chinaport platforms. The results further highlighted the effects of power over trade partners (Ke et al., 2009). Moreover, dominant and large firms have power in deciding which channels are used to book containers. It could be the shipping lines and the shippers, with large volume requests from shipping lines or forwarders. In general, forwarders have the least power in deciding which channels to use. This is consistent with previous studies (for instance, Kurnia et al. (2015)) which have suggested that large organizations are a major force in the technology adoption process.

\section{Contributions, Implications, Limitations}

\subsection{Contributions and Implications}

This research makes substantial contributions to the current understanding of the adoption of information systems and innovation diffusion in the maritime supply chain (e.g., Harris et al. 2015; Hsu et al. 2009; Mondragon et al. 2017; Yang, 2019). The study extends the generic TOE framework by attempting to apply it in the context of the maritime supply chain and revealing some unique adoption factors that were not highlighted previously. Firstly, the study identified information confidentiality as a significant factor. This research responded to the call from Massimino et al. (2018) for research on inter-organizational digital confidentiality by empirically 
confirming the importance of information confidentiality between organizations. Furthermore, this study was among the first to examine the role of ownership structures in information system diffusion research. Organizations with diverse ownership structures react differently in adopting information systems in the maritime supply chain. Finally, the results empirically confirmed that the effects of power-i.e., supply chain partners' power and governmental power-that have been identified in other contexts are also relevant in the context of the maritime supply chain (e.g., Lai et al. 2006; Mondragon et al. 2017).

This study conducted semi-structured interviews across the entire container booking chain, and the results suggest that the impacts of different factors vary among organizations from different tiers. It responded to the call for developing novel and innovative research methods in information system research (Cecez-Kecmanovic et al., 2020). Further, this research sheds light on the research of innovation diffusion in the maritime supply chain and could serve as the basis for future research.

This study also provided practitioners with vital implications that may help to better diffuse technological innovations in this unique context. Leading organizations like MSK and CMA-CGM have introduced different inter-organizational information systems to improve digitalization in the past few years (CMA-CGM, 2020; White, 2018), while tech start-ups like Flexport and Freighthub are transforming the traditional business model of the maritime supply chain (WTO, 2019). The findings of this study have significant implications for managers in these organizations: important factors need to be taken into consideration when diffusing inter-organizational information systems in the maritime supply chain. First, service providers should take the information confidentiality of information systems into consideration during the design stage. Further, along with investing in the development of the information system itself, improving service quality is also essential. Third, organizations need to realize the differences between firms with various ownership structures. Fourth, there is significant power emanating from the authorities; government legislation imposing inter-organizational information systems could result in a higher degree of adoption (Mondragon et al. 2017). Moreover, initiatives from dominant and large organizations-i.e., shipping lines and shippers - could help to better diffuse inter-organizational information systems in the maritime supply chain.

\subsection{Limitations and Future Research}

The authors acknowledge the limitations of this study, some of which may spur future research avenues. First, this study was explorative in nature; future research could examine and generalize the results with quantitative methods, such as surveys. Second, since the diffusion of interorganizational information systems is still in its infancy, this study focused on the early phase of diffusion, i.e., the adoption stage. Future studies could investigate the whole diffusion stage (e.g., Zhu et al., 2006). Moreover, this study was conducted at firm level; future research could apply innovation diffusion theories and frameworks at an individual level-e.g., the Technology Acceptance Model (TAM) (Davis et al. 1989) and the Unified Theory of Acceptance and Use of Technology (UTAUT) (Venkatesh et al. 2003) - to empirically test how individuals adopt interorganizational information systems in this context (such as employees of organizations in the chain). Finally, this study investigated the adoption factors of inter-organizational information booking 
systems, such as open platform; future studies could test the results from the perspectives of other technological innovations, such as blockchain technology and cloud computing. This could provide a more comprehensive understanding of the adoption behavior relating to technological innovation in the maritime supply chain.

\section{Conclusion}

This study employed a multi-method approach to explore the adoption behavior relating to interorganizational information systems in the maritime supply chain at firm level. Twenty-five case studies across four tiers in the maritime supply chain were conducted, and open platform was used as an exemplar in this research. The generic TOE framework was employed as the theoretical basis in this study, and it was found that the adoption of inter-organizational information systems in this context is not only affected by the factors identified in previous literature, such as relative advantage, ease of use, firm size, and top management support, but also by other salient factors, such as industrial characteristics, information confidentiality, supply chain partners' power, governmental power, and ownership structure. Moreover, such factors have a diverse impact on organizations across different tiers with regard to the adoption of inter-organizational information systems for communication and information sharing. Generally speaking, the adoption is more complex in this context, due to the complicated relationship of supply chain partners in the maritime transportation industry. Digitalization and many technological advances provide opportunities for stakeholders in the chain to improve efficiency, enhance productivity, and reduce the impact caused by environmental uncertainty. The authors hope that this work will be a starting point for future studies of the diffusion of diverse information systems and technologies in the maritime supply chain. 


\section{References}

Ahmed, R., Oliver, G., Rahim, M., 2020. Understanding potentials of Cloud ERP adoption by large organisations: A case study. In: Twenty-Third Pacific Asia Conference on Information Systems (PACIS), Dubai, AUE, 2020.

Alphaliner, 2020. Alphaliner Top 100 Shipping lines.

Available at: https://alphaliner.axsmarine.com/PublicTop100/ (last accessed 20.03.2020).

Alsheibani, S.A., Cheung, D., Messom, D., 2019. Factors inhibiting the adoption of Artificial Intelligence at organizational-level: A preliminary investigation. In: Twenty-fifth Americas Conference on Information Systems, Cancun, 2019.

Auerbach, C., Silverstein, L. B., 2003. Qualitative data: An introduction to coding and analysis, NYU press.

Baker, J., 2012. The Technology-organization-environment framework. In: Information systems theory. 231-245. Springer, New York, NY.

Bax, R., 2018. 2018 Top 50 Ocean Freight Forwarders. Available at: https://hub.controlpay.com/controlpay-scm-logistics-en/2018-top-50-ocean-freightforwarders (last accessed 28.04.2020).

Cao, Q., Jones, D.R., Sheng, H., 2014. Contained nomadic information environments: Technology, organization, and environment influences on adoption of hospital RFID patient tracking. Information \& Management. 51(2), 225-239.

Cecez-Kecmanovic, D., Davison, R.M., Fernandez, W., Finnegan, P., Pan, S.L., Sarker, S., 2020. Advancing Qualitative IS Research Methodologies: Expanding Horizons and Seeking New Paths. Journal of Association for Information Systems. 21(1), 246-263.

Chan, J.H., Reiner, D., 2019. Evolution in inter-firm governance along the transport biofuel value chain in Maritime Silk Road countries. Transportation Research Part E. 122, 268-282.

Chao, S.L., Lin, P.S., 2009. Critical factors affecting the adoption of container security service: The shippers' perspective. International Journal of Production Economics. 122(1), 67-77.

Choi, T.M., Cheng, T.C.E., Zhao, X., 2016. Multi-methodological Research in operations management. Production and Operations Management. 25(3), 379-389.

Choi, T.M., Chow, P.S., Liu, S.C., 2013. Implementation of fashion ERP systems in China: Case study of a fashion brand, review and future challenges. International Journal of Production Economics. 146(1), 70-81.

Choi, T.M., Feng, L., Li, R., 2020. Information disclosure structure in supply chains with rental service platforms in the blockchain technology era. International Journal of Production Economics. 221, 107473.

CMA-CGM, 2020. CMA CGM Mobile App: new design, new features. Available at: http://www.cma-cgm.com/latest-news (last accessed 18.04.2020). 
Davis, F.D., Bagozzi, R.P., Warshaw, P.R., 1989. User acceptance of computer technology: a comparison of two theoretical models. Management Science. 35(8), 982-1003.

de Mattos, C.A., Laurindo, F.J.B., 2017. Information technology adoption and assimilation: Focus on the suppliers portal. Computers in Industry. 85, 48-57.

Ge, L., Voß, S., 2009. ERP application in China: An overview. International Journal of Production Economics. 122(1), 501-507.

Gunasekaran, A., Subramanian, N., Papadopoulos, T., 2017. Information technology for competitive advantage within logistics and supply chains: A review. Transportation Research Part E: Logistics and Transportation Review. 99, 14-33.

Harris, I., Wang, Y., Wang, H., 2015. ICT in multimodal transport and technological trends: Unleashing potential for the future. International Journal of Production Economics. 159, 88103.

Hsu, W.K.K., Huang, S.H.S., Yu, H.F., 2009. Shipper behavior to use EC services in liner shipping. International Journal of Production Economics. 122(1), 56-66.

Illin, V., Ivetic, J., Simic, D., 2017. Understanding the determinants of e-business adoption in ERPenabled firms and non-ERP-enabled firms: A case study of the Western Balkan Peninsula. Technological Forecasting and Social Change. 125, 206-223.

Johns, G., 2006. The essential impact of context on organizational behavior. The Academy of Management Review. 31(2), 386-408.

Ke, W., Liu, H., Wei, K.K., Gu, j., Chen, H., 2009. How do mediated and non-mediated power affect electronic supply chain management system adoption? The mediating effects of trust and institutional pressures. Decision Support Systems. 46(4), 839-851.

Kuan, K.K.Y., Chau, P.Y.K., 2001. A perception-based model for EDI adoption in small businesses using a technology-organization-environment framework. Information \& Management. 38(8), 507-521.

Kurnia, S., Karnali, R.J., Rahim, M.M., 2015. A qualitative study of business-to-business electronic commerce adoption within the Indonesian grocery industry: A multi-theory perspective. Information \& Management. 52(4), 518-536.

Lai, K.H., Wong, C.W.Y., Cheng, T.C.E., 2006. Institutional isomorphism and the adoption of information technology for supply chain management. Computers in Industry. 57(1), 93-98.

Lin, H.F., 2014. Understanding the determinants of electronic supply chain management system adoption: Using the technology-organization-environment framework. Technological Forecasting and Social Change. 86, 80-92.

Lin, H.F., 2017. Antecedents and consequences of electronic supply chain management diffusion. The International Journal of Logistics Management. 28(2), 699-718.

Lu, C.S., Lai, K.H., Cheng, T.C.E., 2007. Application of structural equation modeling to evaluate the intention of shippers to use Internet services in liner shipping. European Journal of 
Operational Research. 180(2), 845-867.

Massimino, B., Gray, J.V., Lan, Y., 2018. On the inattention to digital confidentiality in operations and supply chain research. Production and Operations Management. 27(8), 1492-1515.

Mondragon, A.E.C., Mondragon, C.E.C., Coronado, E.S., 2017. ICT adoption in multimodal transport sites: Investigating institutional-related influences in international seaports terminals. Transportation Research Part A: Policy and Practice. 97, 69-88.

Ngai, E.W.T., Lai, K.H., Cheng, T.C.E. 2008. Logistics information systems: the Hong Kong experience. International Journal of Production Economics. 113(1), 223-234.

Nguyen, H.O., 2013. Critical factors in e-business adoption: Evidence from Australian transport and logistics companies. International Journal of Productions Economics. 146(1), 300-312.

Oliveira, T., Martins, M.F., 2011. Literature review of information technology adoption models at firm level. Electronic Journal of Information Systems Evaluation. 14(1), 110-121.

Oliveira, T., Thomas, M., Espadanal, M., 2014. Assessing the determinants of cloud computing adoption: An analysis of the manufacturing and service sectors. Information \& Management. 51(5), 497-510.

Perry, C., 1998. Processes of a case study methodology for postgraduate research in marketing. European Journal of Marketing. 32(9/10), 785-802.

Reyes, P.M., Li, S., Visich, J.K., 2016. Determinants of RFID adoption stage and perceived benefits. European Journal of Operational Research. 254(3), 801-812.

Rogers, E.M., 1995. Diffusion of innovations. Free Press. New York.

Smart, A.U., Bunduchi, R., Gerst, M., 2010. The costs of adoption of RFID technologies in supply networks. International Journal of Operations \& Production Management. 30(4), 423-447.

Tornatzky, L.G. Fleischer, M., 1990. The process of technological innovation. Lexington, MA: Lexington Books.

Tradelens, 2020. Digitizing the global supply chain. Available at: https://www.tradelens.com/about (last accessed 08.06.2020).

Tu, M., 2018. An exploratory study of Internet of Things (IoT) adoption intention in logistics and supply chain management. The International Journal of Logistics Management. 29(1), 131151.

UNCTAD, 2016. Review of Maritime Transport 2016. United Nations Publication. Sales No. E.16.II.D.7. New York and Geneva.

UNCTAD, 2019. Review of Maritime Transport 2019. United Nations Publication. Sales No. E.19.II.D.20. New York and Geneva.

van Baalen, P., Zuidwijk, R., van, Nunen, J., 2009. Port inter-organizational information systems: Capabilities to service global supply chains. Foundations and Trends ${ }^{\circledR}$ in Technology, Information and Operations Management. 2(2-3), 81-241. 
Venkatesh, V., Bala, H., Sambamurthy, V., 2016. Implementation of an information and communication technology in a developing country: A multimethod longitudinal study in a bank in India. Information Systems Research. 27(3), 558-579.

Venkatesh, V., Davis, F.D., Morris, M.G., 2007. Dead or alive? The development, trajectory and future of technology adoption research. Journal of the Association for Information Systems. $8(4), 267-286$.

Venkatesh V., M.G. Morris., Davis, G.B., Davis, F.D., 2003. User acceptance of information technology: Toward a unified view. MIS Quarterly. 27(3), 425-478.

Wacker, J.G., 1998. A definition of theory: research guidelines for different theory-building research methods in operations management. Journal of Operations Management 16(4), 361385.

Walsham, G., Robey, D., Sahay, S., 2007. Foreword: Special issue on information systems in developing countries. MIS quarterly, 317-326.

Wang, J., Liu, J., Zhang, X., 2020. Service purchasing and market-entry problems in a shipping supply chain. Transportation Research Part E: Logistics and Transportation Review. 136, 101895.

Wang, Y.M., Wang, Y.S., Yang, Y.F., 2010. Understanding the determinants of RFID adoption in the manufacturing industry. Technological Forecasting and Social Change. 77(5), 803-815.

Wei, J., Lowry, P.B., Seedorf, S., 2015. The assimilation of RFID technology by Chinese companies: A technology diffusion perspective. Information \& Management. 52(6), 628-642.

White, M., 2018. A global trade platform using blockchain technology aimed at improving the cost of transportation, lack of visibility and inefficiencies with paper-based processes. Available at: https://www.ibm.com/blogs/blockchain/2018/01/digitizing-global-trade-maersk-ibm/ (last accessed 08.01.2020).

Woo, S.H., Pettit, S.J., Kwak, D.W., Beresford, A.K.C., 2011. Seaport research: A structural literature review on methodological issues since the 1980s. Transportation Research Part A: Policy and Practice. 45(7), 667-685.

WTO., 2019. World Trade Report 2019: The future of services trade. Geneva: WTO.

Wu, I.L., Chuang, C.H., 2010. Examining the diffusion of electronic supply chain management with external antecedents and firm performance: a multi-stage analysis. Decision Support Systems. 50(1), 103-115.

Yang, C.S., 2019. Maritime shipping digitalization: blockchain-based technology applications, future improvements, and intention to use. Transportation Research Part E: Logistics and Transportation Review. 131, 108-117.

Yin R. K., 2018. Case study research and applications: design and methods $\left(6^{\text {th }}\right.$ edn). Thousand Oaks, CA: Sage.

Zhu, K., Kraemer, K.L., Xu, S., 2003. Electronic business adoption by European firms: a cross- 
country assessment of the facilitators and inhibitors. European Journal of Information Systems. 12(4), 251-268.

Zhu, K., Kraemer, K.L., Xu, S., 2006. The process of innovation assimilation by firms in different countries: A technology diffusion perspective on E-business. Management Science 52(10), 1557-1576. 